\title{
Unprotected Left-Main Coronary Angioplasty in the Elderly in a High Volume Catheterization Centre without On-Site Surgery Facilities: Immediate and Medium Term Outcome-The Old-Placet Registry
}

\author{
A. Gagnor, F. Tomassini, E. Cerrato, C. Rolfo, A. Gambino, S. Giolitto, \\ E. Favro, M. Bollati, E. Tizzani, and F. Varbella \\ Ospedale degli Infermi, ASL TO 3, Via Rivalta 27, Rivoli, 10098 Turin, Italy \\ Correspondence should be addressed to A. Gagnor; gagnora@gmail.com
}

Received 26 August 2014; Revised 4 February 2015; Accepted 11 February 2015

Academic Editor: Arnon Blum

Copyright (C) 2015 A. Gagnor et al. This is an open access article distributed under the Creative Commons Attribution License, which permits unrestricted use, distribution, and reproduction in any medium, provided the original work is properly cited.

We aim to assess clinical feasibility and efficacy of unprotected left main (ULM) percutaneous coronary intervention (PCI) in patients older than 75 years over a 6-year period and with 2-year follow-up demonstrating that PCI is a feasible revascularization strategy even in absence of on-site cardiothoracic support. Nevertheless, the outcome of these high-risk patients is still hampered by a sensible in-hospital mortality rate. Older patients have a higher mortality at follow-up (10.0 versus $0.8 \%, P=0.014$ ), while younger patients have a low mortality after the acute phase (15.7 versus $8.4 \%, P=0.15)$.

\section{Introduction}

Unprotected left main (ULM) coronary disease incidence during diagnostic coronary angiography ranges between 4 and $7 \%[1]$ and increases with age $[2,3]$. Even recent guidelines [4] consider coronary artery bypass graft (CABG) the preferred revascularization strategy for ULM disease, especially when distal bifurcation is involved and in presence of diffuse multivessel coronary disease [5]. Nevertheless clinical profile and age in specific can dramatically increase the surgical risk [6] and so, notwithstanding the encouraging results obtained in elective patients with ULM coronary disease treated with percutaneous coronary intervention (PCI) and drug-eluting stents (DES) [7-10], results in older population with ULM disease (generally excluded by randomized trials) are unclear. In this study, we specifically evaluated the feasibility and the efficacy of percutaneous ULM coronary disease treatment in older population (more than 75 years old) in a group of patients referred to a centre without onsite cardiothoracic surgical support in the contest of acute coronary syndrome (ACS).

\section{Methods}

This is a spontaneous single-centre registry; catheterization laboratory and general characteristics are described elsewhere [11]. We retrospectively enrolled all the patients with unprotected left main coronary artery disease in the contest of acute coronary syndrome (ACS) treated with percutaneous coronary angioplasty in our institution between January 2003 and January 2010; a dedicated database (Cardioplanet, EBIT$\mathrm{AE}, \mathrm{IT})$ was used to obtain clinical and procedural data and a clinical-event committee-based study (F. Tomassini and A. Gambino) was used for end point adjudication. All angiograms were reviewed to assess primary involvement of ULM and technique and procedural details. Due to the lack of on-site cardiothoracic surgical team in our institution, the decision to proceed PCI instead of CABG was primarily dependent on hemodynamic stability of the patients, the high-surgical risk (e.g., critical ill condition, EUROSCORE), and the technical feasibility of the percutaneous procedure, so PCI was performed because of the unacceptable delay in reaching the nearest cardiac surgery for emergency bypass in 
an emergency setting. Nonurgent revascularization patients were excluded from the study as they were discussed with cardiosurgeon and, in absence of clinical or technical contraindication, were treated with CABG.

Cardiogenic shock was defined as systolic blood pressure persistently below $90 \mathrm{mmHg}$.

Coronary flow was defined according to Thrombolysis in Myocardial Infarction (TIMI) grade [12]. Procedural success was defined as $<20 \%$ residual stenosis, TIMI 3 flow without patient's death or in-hospital target vessel failure (TVF). Significant disease in vessel different from ULM was defined as $>50 \%$ stenosis. Cardiac death was defined as any death due to cardiac cause, procedure-related deaths, and death of unknown cause. Myocardial infarction (MI) was defined as any elevation of creatine-kinase level or its $\mathrm{MB}$ isoenzyme up to 3 times the upper normal limit [13]. Target lesion revascularization (TLR) was defined as any revascularization procedure performed because of angiographic restenosis at the site of the lesion treated associated with clinical and/or objective evidence of inducible myocardial ischemia. Procedure strategy (balloon predilatation, stent selection, use of intraaortic balloon pump, and anticoagulation or antiplatelet regimen) was left to operator discretion.

Logistic EUROSCORE was adopted to assess the cardiac surgical or percutaneous mortality risk $[14,15]$.

Primary end point was in-hospital target vessel failure (TVF) defined as death from cardiac cause, myocardial infarction attributable to the target vessel, or clinically driven target vessel revascularization (TVR). Secondary end points were (1) death for any cause during hospitalization and (2) death for any cause at two years follow-up and (3) TVF at twoyear follow-up.

All patients were discharged on dual antiplatelet therapy (aspirin and clopidogrel or ticlopidine) for twelve months irrespective from the selected stent.

All survived patients with no clinical contraindications were scheduled for angiographic follow-up at six months. Two-year clinical follow-up data were obtained from outpatient clinic visit or direct telephone contact. Due to the observational design of this registry ethical committee approval was waived.

2.1. Statistical Analysis. All continuous results are presented as mean \pm standard deviation (SD). Chi-square and unpaired Student's $t$-test are used to compare, respectively, ordinal and continuous variables. A $P<0.05$ value was considered statistically significant. 95\% confidence intervals (CIs) for proportions are calculated by the Wilson method. Independent predictors of in-hospital and long-term outcomes were analysed using Cox proportional hazards regression model. The results are reported as adjusted odds ratio (OR) with associated $95 \%$ confidence intervals (CI). A two-tailed $P$ value $<0.05$ was established as the level of statistical significance for all tests. A logistic regression analysis identified the variables that were significantly and independently associated with in-hospital TVF. Survival curves were constructed using the Kaplan-Meier method to analyse freedom target lesion failure (TLF); statistical analyses were carried out using SPSSPASW 18.0 (IBM, Armonk, NY, USA) except for survival curves that were generated with $\mathrm{R}$ program version 3.0.2. ( $\mathrm{R}$ Core Team, 2013, http://www.r-project.org/).

\section{Results}

During the observed period we have treated 200 patients with ULM disease; baseline characteristics are shown in Table 1. The high-risk profile of this cohort includes acute MI diagnosis in $34.5 \%$ with $22 \%$ with ST-elevation myocardial infarction (STEMI) presentation, multivessel coronary artery disease $(\mathrm{CAD})$ in $63.0 \%$, severely depressed ejection fraction (EF) $(<35 \%)$ in $18.5 \%$, and previous PCI in $19.5 \%$ accounting for a mean additive EuroSCORE value of 8 (interquartile range $4-13$ ).

70 patients $(35 \%)$ were older than 75 years. Older group had a smaller prevalence of normal ejection fraction at admission (28.5 versus $43.8 \%, P=0.024$, IC $0.27-0.95$ ), higher recent or prior malignancy diagnosis prevalence (18.5 versus $6.9 \%, P=0.013$, IC 1.2 to 7.5 ), lower smoke habit prevalence (35.1 versus $67.6 \%, P<0.001$, IC 0.15 to 0.51 ), and higher clinical risk (EuroSCORE additive $>1338.5$ versus 20.7, $P=0.006$, IC 1.2 to 4.5; Logistic Euroscore $41.91 \pm 26.77$ versus $7.80 \pm .11 .25, P<0.0001$, IC 1.01 to 1.03$)$. A non-STelevation myocardial infarction (NSTEMI) presentation was present in 14.2 versus $11.5 \%$ ( $P=0.006$, IC 1.38 to 7.7$)$.

Main angiographic and procedural characteristics are summarized in Table 2. Pre-procedural hemodynamic instability was present in $44 \%$ of patients and $16 \%$ of patients presented in cardiogenic shock requiring inotropic support or cardiopulmonary resuscitation maneuvers (no significative differences in the two populations). Adjunctive $6 \%$ of patients experienced cardiogenic shock during the procedure with a cumulative incidence of intra-procedural cardiac arrest in $3.5 \%$. Intra-aortic balloon pump (IABP) was used in majority of cases $(75.5 \%)$ with high prevalence in both populations (81.4 versus $72.3 \%, P=0.17$, IC 0.8 to 3.4 ), while GP IIb/IIIa inhibitors were administered in $47.5 \%$ with higher prevalence in the younger population (53.0 versus $37.1 \%, P=0.038$, IC 0.28 to 0.94 ).

ULM distal bifurcation involvement was present in $88.5 \%$ (88.5 versus $88.4, P=1.0$, IC 0.40 to 2.5 ); a provisional stenting technique was used in the majority of the cases $(67.5 \%)$ in both populations (75.7 versus $63.7 \%, P=0.07$, IC 0.95 to 3.5). Calcified lesions were more frequent in older population (60.0 versus $26.9 \%, P<0.0001$, IC 2.2 to 7.5 ).

Drug eluting stent (DES) was used in the majority of cases $(86.0 \%, 82.8$ versus $87.6 \%, P=0.39$, IC 0.3 to 1.5$)$ with the exclusion of patients with known contraindications. Intravascular ultrasound (IVUS) guidance was adopted only in $12.5 \%$ of procedures and was mostly reserved to younger patients ( 16.1 versus $5.7 \%, P=0.04$, IC 0.10 to 0.95 ). Routine high pressure postdilatation with noncompliant balloon was performed in $76.5 \%$ ( 82.8 versus $73.0 \%, P=0.16$, IC 0.85 to 3.7). Angiographic follow-up was more frequent in younger population (76.1 versus $55.7 \%, P=0.003$, OR 0.3 , IC 0.21 to $0.73)$.

Angiographic success was obtained in $95.0 \%$ of patients (95.7 versus $95.5 \%, P=0.73$, IC 0.31 to 5.0 ), but procedural success was sensibly lower with a cumulative in-hospital TVF 
TABLE 1: Baseline characteristics; ${ }^{*}$ creatinine $>2.0 \mathrm{mg} / \mathrm{dL}$. Numbers are values and percentages or mean and standard deviation (SD) as appropriate. PCI percutaneous coronary angioplasty STEMI: ST-elevation myocardial infarction; NSTEMI: non-ST-elevation myocardial infarction; CAD: coronary artery disease.

\begin{tabular}{|c|c|c|c|c|c|}
\hline & Overall (200) & $>75$ Y.OLD $(70)$ & $<75$ Y.OLD (130) & OR (CI 95\%) & $P$ value \\
\hline \multicolumn{6}{|l|}{ Clinical characteristics } \\
\hline Age (years) & $69.7 \pm 9.6$ & $79.49 \pm 3.72$ & $64.47 \pm 7.56$ & & $<0.0001$ \\
\hline Male gender & $157(78.5)$ & $51(72.8)$ & $106(81.5)$ & $0.6(0.3$ to 1.2$)$ & 0.15 \\
\hline Left ventricle ejection fraction $>55 \%$ & $77(38.5)$ & $20(28.5)$ & $57(43.8)$ & $0.5(0.27$ to 0.95$)$ & 0.02 \\
\hline Left ventricle ejection fraction $<35 \%$ & $37(18.5)$ & $17(24.2)$ & $20(15.3)$ & $1.7(0.85$ to 3.60$)$ & 0.08 \\
\hline Chronic kidney disease ${ }^{*}$ & $26(13.0)$ & $11(15.7)$ & $15(11.5)$ & $1.4(0.61$ to 3.3$)$ & 0.26 \\
\hline Prior PCI & $39(19.5)$ & $12(17.1)$ & $27(20.7)$ & $0.78(0.37$ to 1.6$)$ & 0.33 \\
\hline Malignancy & $22(11.0)$ & $13(18.5)$ & $9(6.9)$ & $3.0(1.2$ to 7.5$)$ & 0.01 \\
\hline \multicolumn{6}{|l|}{ Cardiac risk factors } \\
\hline Hypertension & $140(70.0)$ & $50(71.4)$ & $90(69.2)$ & $1.1(0.58$ to 2.1$)$ & 0.43 \\
\hline Hypercholesterolemia & $87(43.5)$ & $25(35.7)$ & $62(47.6)$ & $0.61(0.33$ to 1.10$)$ & 0.69 \\
\hline Smoke habit & $114(57.0)$ & $25(35.1)$ & $88(67.6)$ & $0.28(0.15$ to 0.51$)$ & $<0.001$ \\
\hline Family history of CAD & $14(7.0)$ & $2(2.8)$ & $12(9.2)$ & $0.28(0.06$ to 1.3$)$ & 0.76 \\
\hline Diabetes & $48(24.0)$ & $15(21.4)$ & $33(25.3)$ & $0.8(0.40$ to 1.6$)$ & 0.32 \\
\hline \multicolumn{6}{|l|}{ Severity of coronary artery disease } \\
\hline Single vessel disease & $37(18.5)$ & $16(22.8)$ & $21(16.1)$ & $1.5(0.74$ to 3.1$)$ & 0.16 \\
\hline Double vessel disease & $54(27.0)$ & $19(27.1)$ & $35(26.9)$ & $1.0(0.52$ to 1.9$)$ & 0.55 \\
\hline Triple vessel disease & $72(36.0)$ & $26(37.1)$ & $46(35.3)$ & $1.07(0.59$ to 1.9$)$ & 0.46 \\
\hline Isolated left main disease & $37(18.5)$ & $9(12.8)$ & $28(21.5)$ & $0.53(0.23$ to 1.2$)$ & 0.18 \\
\hline \multicolumn{6}{|l|}{ Admission diagnosis } \\
\hline Unstable angina & $131(65.5)$ & $43(61.4)$ & $88(67.6)$ & $0.76(0.41$ to 1.39$)$ & 0.23 \\
\hline Myocardial infarction & $69(34.5)$ & $27(38.5)$ & $42(32.3)$ & $1.3(0.71$ to 2.4$)$ & 0.23 \\
\hline NSTEMI & $25(12.5)$ & $10(14.2)$ & $15(11.5)$ & $3.2(1.38$ to 7.7$)$ & 0.006 \\
\hline STEMI & $44(22.0)$ & $12(17.1)$ & $32(24.6)$ & $0.63(0.30$ to 1.32$)$ & 0.14 \\
\hline \multicolumn{6}{|l|}{ EuroSCORE } \\
\hline Additive $>6$ & $112(56.0)$ & $56(0.8)$ & $56(43.0)$ & $5.2(2.6$ to 10.4$)$ & $<0.001$ \\
\hline Additive $>13$ & $54(27.0)$ & $27(38.5)$ & $27(20.7)$ & $2.3(1.2$ to 4.5$)$ & 0.006 \\
\hline Logistic & $22.9 \pm 25.9$ & $41.9 \pm 26.8$ & $7.8 \pm 11.3$ & $1.02(1.01$ to 1.03$)$ & $<0.0001$ \\
\hline
\end{tabular}

rate of $13 \%$ ( 17.1 versus $10.7 \%, P=0.27$, IC 0.74 to 3.9 ), mainly due to a high cardiac death rate $(11 \%, 15.7$ versus $8.4, P=0.15$, IC 0.82 to 4.9 ). At 2 -year follow-up a major prevalence of death was evident in older population (10.0 versus $0.8 \%, P=0.014$, OR 14.3 with IC 1.7 to 119.0 ) but with a smaller prevalence of TLR (2.9 versus $10.0 \%, P=0.067$, OR 0.2 , IC 0.58 to 1.20 ) resulting in similar TVF at followup (10.0 versus $10.8 \% P=0.866$, OR 0.92 , IC 0.35 to 2.39 ). There were no differences in cumulative outcome (in-hospital and two-year follow-up) in TLF (23.5\%; 27.1 versus $21.5 \%$; $P=0.374$; OR 1.3 ; IC 0.69 to 2.65$)$, myocardial infarction (6.0\%; 7.1 versus $5.4 \% ; P=0.619$; OR 1.35 ; IC 0.41 to 4.42 ), TLR (9.5\%; 7.1 versus $10.8 \% ; P=0.407$; OR 0.63 ; IC 0.2 to $1.8)$, stent thrombosis $(3.5 \%, 5.7$ versus $2.3 \% ; P=0.24$; OR 2.5 ; IC 0.55 to 11.8$)$, and cerebral ischaemic events $(1.0 \% ; 1.4$ versus $\left.0.0^{\prime \prime} ; P=0.35\right)$ with a higher cardiac death rate in the older population $(15.0 \% ; 25.7$ versus $9.2 \% ; P=0.003$; OR 3.4; IC 1.52 to 7.57). All in-hospital cardiac deaths were related to clinical presentation (ACS with cardiogenic shock at presentation without clinical improvement after PCI) while follow-up deaths were for unknown cause or sudden death (Table 3).
At univariate analysis the significant predictors of inhospital TVF in older population were EuroSCORE additive $>13$, STEMI at presentation, severely depressed ventricular function, and cardiogenic shock at presentation while after multiple regression adjustment only cardiogenic shock maintained statistical significance $(P=0.04$, OR 8.9; IC 1.0477.22) (Table 4). Freedom from TLF is depicted in Figure 1 without showing significant differences among groups in long-term follow-up (Log-Rank $P$ value $=0.9)$.

\section{Discussion}

CABG is considered the standard of care for patients with ULM disease $[4,5]$ but PCI is technically feasible by expert operators with a very high percentage of angiographic immediate success $[9,16,17]$. Recently, the SYNTAX trial [18], despite being unable to reach the end point of noninferiority of PCI versus CABG, has shown very promising results in less complex coronary anatomy, substantially confirming data from previous registry [19]; on the other hand the studies that historically gave rise to these recommendations excluded elderly patients and it is well known that age can 
TABLE 2: IABP: aortic balloon pump; BMS: bare metal stent; DES: drug-eluting stent; IVUS: intravascular ultrasound; PCI: percutaneous coronary intervention.

\begin{tabular}{|c|c|c|c|c|c|}
\hline & Overall (200) & $>75$ Y.OLD $(70)$ & $<75$ Y.OLD (130) & OR (CI 95\%) & $P$ value \\
\hline \multicolumn{6}{|l|}{ Procedural complexity } \\
\hline Pre-procedural hemodynamic instability & $88(44.0)$ & $37(52.8)$ & $51(39.2)$ & $1.7(0.96$ to 3.1$)$ & 0.07 \\
\hline Pre-procedural cardiogenic shock & $32(16.0)$ & $12(17.1)$ & $20(15.3)$ & $1.1(0.52$ to 2.49$)$ & 0.84 \\
\hline Peri-procedural cardiogenic shock & $44(22.0)$ & $17(24.2)$ & $27(20.7)$ & $1.2(0.61$ to 2.44$)$ & 0.59 \\
\hline Cardiac arrest during or pre procedure & $7(3.5)$ & $3(7.9)$ & $4(3.0)$ & $1.4(0.30$ to 6.48$)$ & 0.69 \\
\hline Orotracheal intubation during or pre procedure & $18(9.0)$ & $9(12.8)$ & $9(6.9)$ & $1.9(-0.29$ to 1.6$)$ & 0.12 \\
\hline IABP use & $151(75.5)$ & $57(81.4)$ & $94(72.3)$ & $1.6(0.80$ to 3.4$)$ & 0.17 \\
\hline Glycoprotein inhibitors IIb/IIIa & $95(47.5)$ & $26(37.1)$ & $69(53.0)$ & $0.52(0.28$ to -0.94$)$ & 0.038 \\
\hline \multicolumn{6}{|l|}{ Target lesion } \\
\hline Ostial left main & $17(8.5)$ & $6(8.5)$ & $11(8.4)$ & $1.0(0.35$ to 2.8$)$ & 1.0 \\
\hline Mid left main & $6(3.0)$ & $2(2.8)$ & $4(3.0)$ & $0.9(0.16$ to 5.1$)$ & 1.0 \\
\hline Distal left main & $177(88.5)$ & $62(88.5)$ & $115(88.4)$ & $1.0(0.40$ to 2.5$)$ & 1.0 \\
\hline \multicolumn{6}{|l|}{ Lesion complexity } \\
\hline Tortuosity & $6(3.0)$ & $3(4.2)$ & $3(2.3)$ & $1.8(0.37$ to 9.60$)$ & 0.42 \\
\hline Irregular & $38(19.0)$ & $14(20.0)$ & $24(18.4)$ & $1.1(0.53$ to 2.30$)$ & 0.85 \\
\hline Calcified & $77(38.5)$ & $42(60.0)$ & $35(26.9)$ & $4.0(2.20$ to 7.50$)$ & $<0.0001$ \\
\hline Thrombotic & $19(9.5)$ & $5(7.1)$ & $14(10.7)$ & $0.6(0.20$ to 1.80$)$ & 0.46 \\
\hline Eccentric & $67(33.5)$ & $23(32.8)$ & $44(33.8)$ & $0.9(0.51$ to 1.70$)$ & 1.0 \\
\hline In-stent restenosis treatment & $5(2.5)$ & $2(2.8)$ & $3(2.3)$ & $1.2(0.20$ to 7.60$)$ & 1.0 \\
\hline Bifurcation angle $>90^{\circ}$ & $9(4.5)$ & $3(4.2)$ & $6(4.6)$ & $0.9(0.22$ to 3.8$)$ & 1.0 \\
\hline Reference vessel diameter (mm) & $3.68 \pm 0.51$ & $3.66 \pm 0.48$ & $3.69 \pm 0.46$ & $1.1(0.62$ to 1.90$)$ & 0.75 \\
\hline Lesion length $(\mathrm{mm})$ & $20.99 \pm 8.11$ & $20.8 \pm 8.4$ & $21.0 \pm 7.9$ & & 0.81 \\
\hline Diameter stenosis & $80.26 \pm 13.96$ & $80.19 \pm 13.8$ & $80.31 \pm 14.06$ & $1.09(0.62$ to 1.90$)$ & 0.75 \\
\hline \multicolumn{6}{|l|}{ Procedural characteristics } \\
\hline Single stent & $135(67.5)$ & $53(75.7)$ & $82(63.7)$ & $1.8(0.95$ to 3.50$)$ & 0.07 \\
\hline BMS implantation & $28(14.0)$ & $12(17.1)$ & $16(12.3)$ & $1.4(0.65$ to 3.30$)$ & 0.39 \\
\hline DES implantation & $172(86.0)$ & $58(82.8)$ & $114(87.6)$ & $0.6(0.30$ to 1.50$)$ & 0.39 \\
\hline Total stent length per patient $(\mathrm{mm})$ & $20.99 \pm 8.12$ & $20.80 \pm 8.41$ & $21.08 \pm 7.97$ & & 0.50 \\
\hline IVUS guided PCI & $25(12.5)$ & $4(5.7)$ & $21(16.1)$ & $0.3(0.10$ to 0.95$)$ & 0.04 \\
\hline Direct stenting & $57(28.5)$ & $15(21.4)$ & $42(32.3)$ & $0.5(0.29$ to 1.12$)$ & 0.14 \\
\hline High pressure stent post-dilation & $153(76.5)$ & $58(82.8)$ & $95(73.0)$ & $1.7(0.85$ to 3.70$)$ & 0.16 \\
\hline Angiographic Success & $190(95.0)$ & $67(95.7)$ & $123(94.6)$ & $1.2(0.31$ to 5.00$)$ & 0.73 \\
\hline Complete revascularization & $153(76.5)$ & $53(75.7)$ & $100(76.9)$ & $0.9(0.47$ to 1.80$)$ & 0.80 \\
\hline Dye $(\mathrm{mL} ;$ mean $\pm \mathrm{SD})$ & $268.4 \pm 94.0$ & $261.9 \pm 93.5$ & $271.9 \pm 94.4$ & $0.9(0.99$ to 1.03$)$ & 0.47 \\
\hline Follow-up angio & $138(0.69)$ & $39(55.7)$ & $99(76.1)$ & $0.3(0.21$ to 0.73$)$ & 0.003 \\
\hline
\end{tabular}

increase dramatically surgical risk (four-time mortality in over 80 years old group compared with $65-75$ years old patients; $13.5 \%$ versus $3.4 \%, P=0.0004$ ) [6], so, despite the fact that clinical features associated with favourable angioplasty outcomes include younger age, older patients are often considered for ULM PCI [20]. Some nonrandomized data hypothesized that in this subgroup of patients PCI can even offer some advantage in short- and mid-term mortality $[21,22]$.

Our data refers to a single-centre experience, with high activity volume (more than 900 angioplasties (PCI) and 220 primary angioplasties (PPCI) per year [23]), three dedicated operators, and without cardiac surgery on site but with surgical bake-up by 30 minutes ambulance travel. Due to geographical and economical reason, with a very diffuse distribution of catheterization laboratories and a high concentration of cardiac surgery in our territory, most of PCI and PPCI in our region are treated in centres without on-site cardiac surgery [23].

The major findings of this monocentric registry is that our data confirm the high clinical risk $(24.2 \% \mathrm{EF}<35 \%$, $21.4 \%$ diabetes mellitus, $38.5 \%$ myocardial infarction at presentation, Logistic Euroscore $41.9 \pm 26.7$ ) and angiographic complexity (37.1\% with three vessel disease associated with ULM) of ULM disease in an aged population with a relatively high percentage (24.2\%) of periprocedural cardiogenic shock and cardiac arrest requiring resuscitation (7.9\%) at presentation. These data could partially explain the very high IABP utilization (81.4\%), higher than previously reported [16, 24]. Notably, in our registry IABP use in the context of ULM 
TABLE 3: In-hospital and follow-up clinical outcomes. Numbers are values and percentages.

\begin{tabular}{|c|c|c|c|c|c|}
\hline & Overall (200) & $>75$ Y.OLD $(70)$ & $<75$ Y.OLD (130) & OR (CI 95) & $P$ value \\
\hline \multicolumn{6}{|l|}{ In-hospital outcome } \\
\hline Target lesion failure & $26(13.0)$ & $12(17.1)$ & $14(10.7)$ & $1.7(0.74$ to 3.90$)$ & 0.27 \\
\hline Cardiac death & $22(11.0)$ & $11(15.7)$ & $11(8.4)$ & $2.0(0.82$ to 4.91$)$ & 0.15 \\
\hline Myocardial infarction & $8(4.0)$ & $3(4.2)$ & $5(3.8)$ & $1.1(0.25$ to 4.81$)$ & 1.00 \\
\hline Target lesion revascularization & $4(2.0)$ & $3(3.4)$ & $1(0.9)$ & $5.7(0.58$ to 56.6$)$ & 0.12 \\
\hline Stent thrombosis & $5(2.5)$ & $3(3.4)$ & $2(1.8)$ & $2.8(0.46$ to 17.50$)$ & 0.34 \\
\hline Definite & $5(2.5)$ & $3(3.4)$ & $2(1.8)$ & & 0.65 \\
\hline Probable & $0(0.0)$ & $0(0.0)$ & $0(0.0)$ & & 1.00 \\
\hline Cerebral ischemic event & $0(0.0)$ & $0(0.0)$ & $0(0.0)$ & & 1.00 \\
\hline \multicolumn{6}{|l|}{ 2-year follow-up outcome } \\
\hline Target lesion failure & $21(10.5)$ & $7(10.0)$ & $14(10.8)$ & $0.9(0.35$ to 2.39$)$ & 0.86 \\
\hline Cardiac death & $8(4.0)$ & $7(10.0)$ & $1(0.8)$ & $14.3(1.72$ to 119.03$)$ & 0.01 \\
\hline Myocardial infarction & $4(2.0)$ & $2(2.9)$ & $2(1.5)$ & $1.8(0.25$ to 13.6$)$ & 0.53 \\
\hline Target lesion revascularization & $15(7.5)$ & $2(2.9)$ & $13(10.0)$ & $0.2(0.58$ to 1.20$)$ & 0.06 \\
\hline Stent thrombosis & $2(1.0)$ & $1(1.4)$ & $1(0.7)$ & $1.8(0.11$ to 30.3$)$ & 1.0 \\
\hline Definite & $1(0.5)$ & $0(0.0)$ & $1(0.7)$ & & 0.44 \\
\hline Probable & $1(0.5)$ & $1(1.1)$ & $0(0.0)$ & & 1.00 \\
\hline Cerebral ischemic event & $1(0.5)$ & $1(1.4)$ & $0(0.0)$ & & 0.35 \\
\hline \multicolumn{6}{|c|}{ Cumulative outcome (in-hospital and follow-up) } \\
\hline Target lesion failure & $47(23.5)$ & $19(27.1)$ & $28(21.5)$ & 1.3 (0.69 to 2.65$)$ & 0.37 \\
\hline Cardiac death & $30(15.0)$ & $18(25.7)$ & $12(9.2)$ & $3.4(1.52$ to 7.57$)$ & 0.003 \\
\hline Myocardial infarction & $12(6.0)$ & $5(7.1)$ & $7(5.4)$ & 1.3 (0.41 to 4.42$)$ & 0.61 \\
\hline Target lesion revascularization & $19(9.5)$ & $5(7.1)$ & $14(10.8)$ & $0.6(0.20$ to 1.80$)$ & 0.40 \\
\hline Stent thrombosis & $7(3.5)$ & $4(5.7)$ & $3(2.3)$ & $2.5(0.55$ to 11.80$)$ & 0.24 \\
\hline Definite & $6(3.0)$ & $3(4.2)$ & $3(2.3)$ & & 0.42 \\
\hline Probable & $1(0.5)$ & $1(1.4)$ & $0(0.0)$ & & 0.35 \\
\hline Cerebral ischemic event & $1(0.5)$ & $1(1.4)$ & $0(0.0)$ & & 0.35 \\
\hline
\end{tabular}

TABLE 4: Multiple regression analysis for in-hospital TVF in older population.

\begin{tabular}{lcccc}
\hline & \multirow{2}{*}{$P$} & OR & \multicolumn{2}{c}{$95 \%$ CI } \\
& & & LCI & UCI \\
\hline Primary PCI & 0.136 & 4,992 & 0,603 & 41,296 \\
LVEF $<35 \%$ & 0.988 & 0,985 & 0,143 & 6,807 \\
EuroSCORE additive $>13$ & 0.861 & 0,808 & 0,074 & 8,757 \\
Shock & 0.046 & 8,961 & 1,040 & 77,229 \\
\hline
\end{tabular}

PCI: percutaneous coronary angioplasty.

LVEF: left ventricular ejection fraction.

LCI: lower confidence interval.

UCI: upper confidence interval.

OR: odds ratio.

stenting resulted higher as usually reported in contemporary registry. This reflects the attitude in our center in prophylactic use of IABP in high risk PCI. However vascular complications were minor and we did not report a significant influence of IABP use in the main endpoint of the study even after statistical adjustment.

As previously reported [24] the majority of patients presented with distal left main bifurcation involvement $(88.5 \%)$, characteristic related with an adverse prognosis at

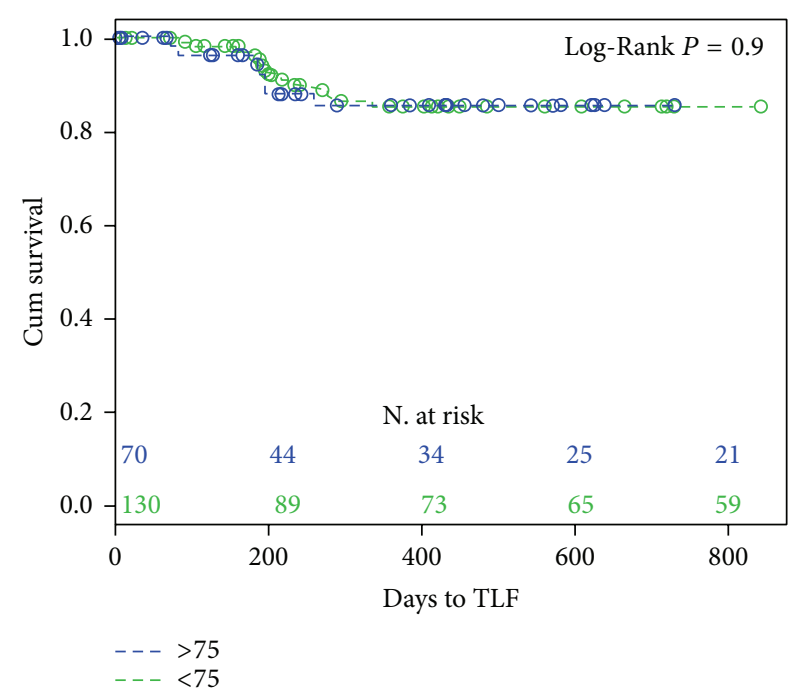

Figure 1

follow-up [25] but in the higher majority of patients it was possible to obtain an adequate final result with a single stent implantation $(75.7 \%)$, strategy related with better outcome 
at follow-up [26]. Severe left main calcification has been identified as an independent predictor of mortality [27] and was more prevalent in the older population (60.0 versus $26.9 \%, P<0.0001)$ but some preparation of the plaque (only 21.4 versus $32.3 \%$ of direct stenting implantation) was obtained in the majority of patients; despite the known prognostic value of ultrasound examination in ULM PCI [28] IVUS was underused in our general (12.5\%) and older $(5.7 \%)$ population, but the device was not available in catheterization laboratory until 2008; this fact could be considered less important by the high prevalence of aggressive noncompliant balloon postdilatation obtained in both populations.

Despite general concerning about long term dual antiplatelet therapy adherence and increased bleeding risk profile, DES have been largely used in the absence of known contraindications; these data are in line with reported of evident advantage in terms of mortality, myocardial infarction, and repeated revascularization at follow-up given by these devices [29].

In agreement with other studies $[9,16,19,21,30]$ most of the deaths occur during in-hospital phase with a trend favouring the younger population during in-hospital phase; at follow-up differences in cardiac death rate diverge in a more significant way with a worse prognosis for older patients. Probably due to the higher prevalence of elective angiographic follow-up, time dependent TLR is higher in younger population and comparable with previous report; notwithstanding the greater attention paid to these patients in postdischarge period TLR rate remains acceptable and consistent with previous literature $[16,31,32]$.

In the older population several characteristics seemed to be related with adverse event at follow-up, but, after multivariate analysis, only cardiogenic shock at presentation maintained an independent prognostic role.

\section{Study Limitations}

This is a retrospective nonrandomized study, with a very selected population and a relative small sample size. Another limitation is the lack of collegial discussion with surgical team in urgent cases or in high-risk patients that might have forced the selection for PCI treatment. Nevertheless, this registry reflects the real current practice in most centres offering $24 \mathrm{~h}$ PCI availability without on-site surgical backup.

\section{Conclusions}

Despite the high clinical risk and the angiographic complexity, ULM PCI in a population older than 75 years old seems to be technically feasible and a good alternative to surgical revascularization particularly in a centre with a high-volume catheterization laboratory and experienced operators with a very large personal case-load per year without in-hospital surgical facilitation. Mortality in this group of patients tends to be quite high but lesser than mortality of untreated patients and the vaster majority of events is concentrated in in-hospital phase. At follow-up older patients prognosis remains worse when compared with a younger population.
Cardiogenic shock at presentation is related to adverse events during acute phase and at follow-up.

\section{Conflict of Interests}

The authors declare that there is no conflict of interests regarding the publication of this paper.

\section{References}

[1] G. Montalescot, D. Brieger, K. A. Eagle et al., "Unprotected left main revascularization in patients with acute coronary syndromes," European Heart Journal, vol. 30, no. 19, pp. 23082317, 2009.

[2] J. Shirani, J. Yousefi, and W. C. Roberts, "Major cardiac findings at necropsy in 366 American octogenarians," The American Journal of Cardiology, vol. 75, no. 2, pp. 151-156, 1995.

[3] H. Hirsch, J. Lazar, K. P. Marzo, and R. M. Steingart, "Percutaneous revascularization for unstable angina in the elderly," Coronary Artery Disease, vol. 11, no. 4, pp. 315-322, 2000.

[4] F. van de Werf, J. Bax, A. Betriu et al., "Management of acute myocardial infarction in patients presenting with persistent STsegment elevation: the task force on the management of STsegment elevation acute myocardial infarction of the European society of cardiology," European Heart Journal, vol. 29, no. 23, pp. 2909-2945, 2008.

[5] S. C. Smith Jr., T. E. Feldman, J. W. Hirshfeld Jr. et al., "ACC/AHA/SCAI 2005 guideline update for percutaneous coronary intervention-summary article: a report of the American college of cardiology/American heart association task force on practice guidelines (ACC/AHA/SCAI writing committee to update the 2001 guidelines for percutaneous coronary intervention)," Journal of the American College of Cardiology, vol. 47, no. 1, pp. 216-235, 2006.

[6] J. Rodés-Cabau, J. DeBlois, O. F. Bertrand et al., "Nonrandomized comparison of coronary artery bypass surgery and percutaneous coronary intervention for the treatment of unprotected left main coronary artery disease in octogenarians," Circulation, vol. 118, no. 23, pp. 2374-2381, 2008.

[7] M. Valgimigli, P. Malagutti, J. Aoki et al., "Sirolimus-eluting versus paclitaxel-eluting stent implantation for the percutaneous treatment of left main coronary artery disease: a combined RESEARCH and T-SEARCH long-term analysis," Journal of the American College of Cardiology, vol. 47, no. 3, pp. 507-514, 2006.

[8] I. Sheiban, E. Meliga, C. Moretti et al., "Long-term clinical and angiographic outcomes of treatment of unprotected left main coronary artery stenosis with sirolimus-eluting stents," American Journal of Cardiology, vol. 100, no. 3, pp. 431-435, 2007.

[9] E. Meliga, H. M. Garcia-Garcia, M. Valgimigli et al., "Longest available clinical outcomes after drug-eluting stent implantation for unprotected left main coronary artery disease. The DELFT (Drug Eluting stent for LeFT main) registry," Journal of the American College of Cardiology, vol. 51, no. 23, pp. 2212-2219, 2008.

[10] A. Chieffo, V. Magni, A. Latib et al., "5-year outcomes following percutaneous coronary intervention with drug-eluting stent implantation versus coronary artery bypass graft for unprotected left main coronary artery lesions: the Milan experience," JACC: Cardiovascular Interventions, vol. 3, no. 6, pp. 595-601, 2010. 
[11] A. Gagnor, F. Tomassini, E. Romagnoli et al., "Percutaneous left main coronary disease treatment without on-site surgery backup in patients with acute coronary syndromes: immediate and 2-year outcomes," Catheterization and Cardiovascular Interventions, vol. 79, no. 6, pp. 979-987, 2012.

[12] H. S. Mueller, A. Dyer, and M. A. Greenberg, "The thrombolysis in myocardial infarction (TIMI) trial. Phase I findings," The New England Journal of Medicine, vol. 312, no. 14, pp. 932-936, 1985.

[13] D. E. Cutlip, S. Windecker, R. Mehran et al., "Clinical end points in coronary stent trials: a case for standardized definitions," Circulation, vol. 115, no. 17, pp. 2344-2351, 2007.

[14] E. Romagnoli, F. Burzotta, C. Trani et al., "EuroSCORE as predictor of in-hospital mortality after percutaneous coronary intervention," Heart, vol. 95, no. 1, pp. 43-48, 2009.

[15] S. A. M. Nashef, F. Roques, P. Michel, E. Gauducheau, S. Lemeshow, and R. Salamon, "European system for cardiac operative risk evaluation (EuroSCORE)," European Journal of Cardio-thoracic Surgery, vol. 16, no. 1, pp. 9-13, 1999.

[16] P. E. Buszman, P. P. Buszman, R. S. Kiesz et al., "Early and longterm results of unprotected left main coronary artery stenting. The LE MANS (Left Main Coronary Artery Stenting) registry," Journal of the American College of Cardiology, vol. 54, no. 16, pp. 1500-1511, 2009.

[17] S.-J. Park, Y.-H. Kim, B.-K. Lee et al., "Sirolimus-eluting stent implantation for unprotected left main coronary artery stenosis: comparison with bare metal stent implantation," Journal of the American College of Cardiology, vol. 45, no. 3, pp. 351-356, 2005.

[18] P. W. Serruvs, M.-C. Morice, A. P. Kappetein et al., "Percutaneous coronary intervention versus coronary-artery bypass grafting for severe coronary artery disease," The New England Journal of Medicine, vol. 360, no. 10, pp. 961-972, 2009.

[19] D.-W. Park, K. B. Seung, Y.-H. Kim et al., "Long term safety and efficacy of stenting versus coronary artery by-pass grafting for unprotected left main coronary artery disease: 5 years results from the MAIN COMPARE (revascularization for unprotected left main coronary artery stenosis: comparison of percutaneous coronary angioplasty versus surgical revascularization) registry," Journal of the American College of Cardiology, vol. 56, no. 2, pp. 117-124, 2010.

[20] F. G. Kushner, M. Hand, S. C. Smith et al., "2009 focused updates: ACC/AHA guidelines for the management of patients with ST-elevation myocardial infarction (updating the 2004 guideline and 2007 focused update): a report of the American College of Cardiology Foundation/American Heart Association task force practice guidelines," Catheterization and Cardiovascular Interventions, vol. 75, p. 1143, 2010.

[21] R. Ghenim, J. Roncalli, A. M. Tidjane et al., "One-year follow-up of nonrandomized comparison between coronary artery bypass grafting surgery and drug-eluting stent for the treatment of unprotected left main coronary artery disease in elderly patients (Aged $\geq 75$ years)," Journal of Interventional Cardiology, vol. 22, no. 6, pp. 520-526, 2009.

[22] L. J. Dacey, D. S. Likosky, T. J. Ryan Jr. et al., "Long term survival after surgery versus percutaneous intervention in octagenarians with multivessel coronary disease," Annals of Thoracic Surgery, vol. 84, no. 6, pp. 1904-1911, 2007.

[23] F. Varbella, A. Gagnor, F. Tomassini et al., "Come iniziare ad eseguire procedure interventistiche coronariche e carotidee complesse senza back-up chirurgico," Il Giornale Italiano di Cardiologia Invasiva, vol. 2, pp. 25-34, 2010.

[24] J. Mehilli, A. Kastrati, R. A. Byrne et al., "Paclitaxel-versus sirolimus-eluting stents for unprotected left main coronary artery disease," Journal of the American College of Cardiology, vol. 53, no. 19, pp. 1760-1768, 2009.

[25] G. G. L. Biondi-Zoccai, M. Lotrionte, C. Moretti et al., "A collaborative systematic review and meta-analysis on 1278 patients undergoing percutaneous drug-eluting stenting for unprotected left main coronary artery disease," American Heart Journal, vol. 155, no. 2, pp. 274-283, 2008.

[26] T. Palmerini, A. Marzocchi, C. Tamburino et al., "Impact of bifurcation technique on 2-year clinical outcomes in 773 patients with distal unprotected left main coronary artery stenosis treated with drug-eluting stents," Circulation: Cardiovascular Interventions, vol. 1, no. 3, pp. 185-192, 2008.

[27] W. A. Tan, H. Tamai, S.-J. Park et al., "Long-term clinical outcomes after unprotected left main trunk percutaneous revascularization in 279 patients," Circulation, vol. 104, no. 14, pp. 1609-1614, 2001.

[28] S.-J. Park, Y.-H. Kim, D.-W. Park et al., "Impact of intravascular ultrasound guidance on long-term mortality in stenting for unprotected left main coronary artery stenosis," Circulation: Cardiovascular Interventions, vol. 2, no. 3, pp. 167-177, 2009.

[29] S. B. Pandya, Y.-H. Kim, S. N. Meyers et al., "Drug-eluting versus bare-metal stents in unprotected left main coronary artery stenosis. A meta-analysis," JACC: Cardiovascular Interventions, vol. 3, no. 6, pp. 602-611, 2010.

[30] M. A. M. Beijk, S. Z. H. Rittersma, K. T. Koch et al., "Long-term follow-up after nonurgent percutaneous coronary intervention in unprotected left main coronary arteries," Catheterization and Cardiovascular Interventions, vol. 75, no. 7, pp. 1026-1036, 2010.

[31] C. Godino, G. Parodi, S. Furuichi et al., "Long-term followup (four years) of unprotected left main coronary artery disease treated with paclitaxel-eluting stents (from the TRUE Registry)," EuroIntervention, vol. 5, no. 8, pp. 906-916, 2010.

[32] G. G. L. Biondi-Zoccai, E. Giraudi, C. Moretti et al., "Impact of routine angiographic follow-up after percutaneous coronary drug-eluting stenting for unprotected left main disease: the Turin Registry," Clinical Research in Cardiology, vol. 99, no. 4, pp. 235-242, 2010. 


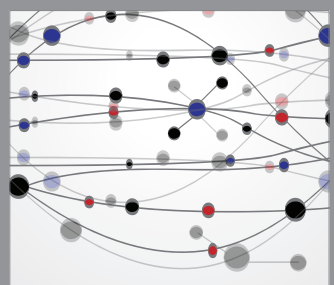

The Scientific World Journal
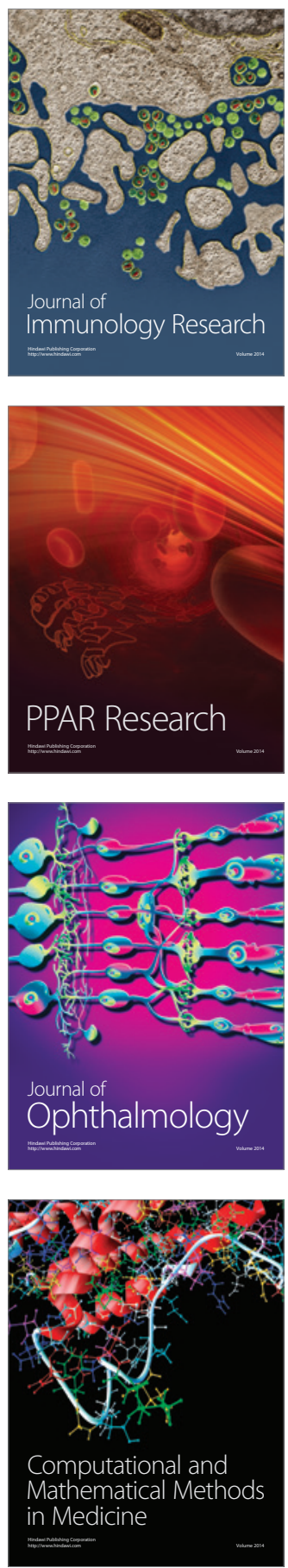

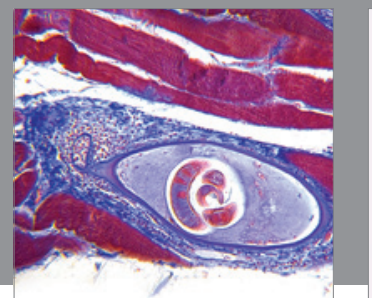

Gastroenterology

Research and Practice
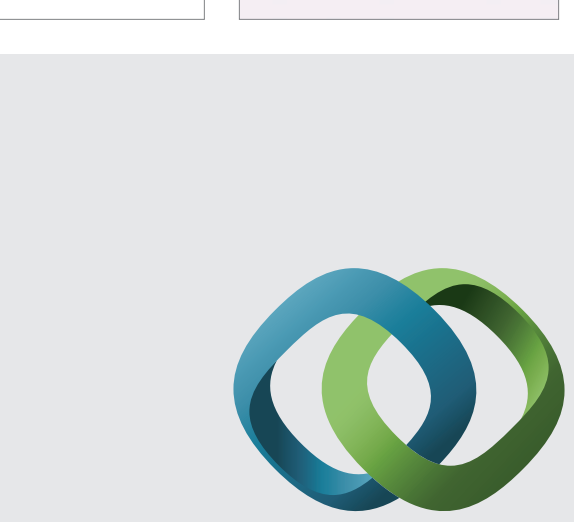

\section{Hindawi}

Submit your manuscripts at

http://www.hindawi.com
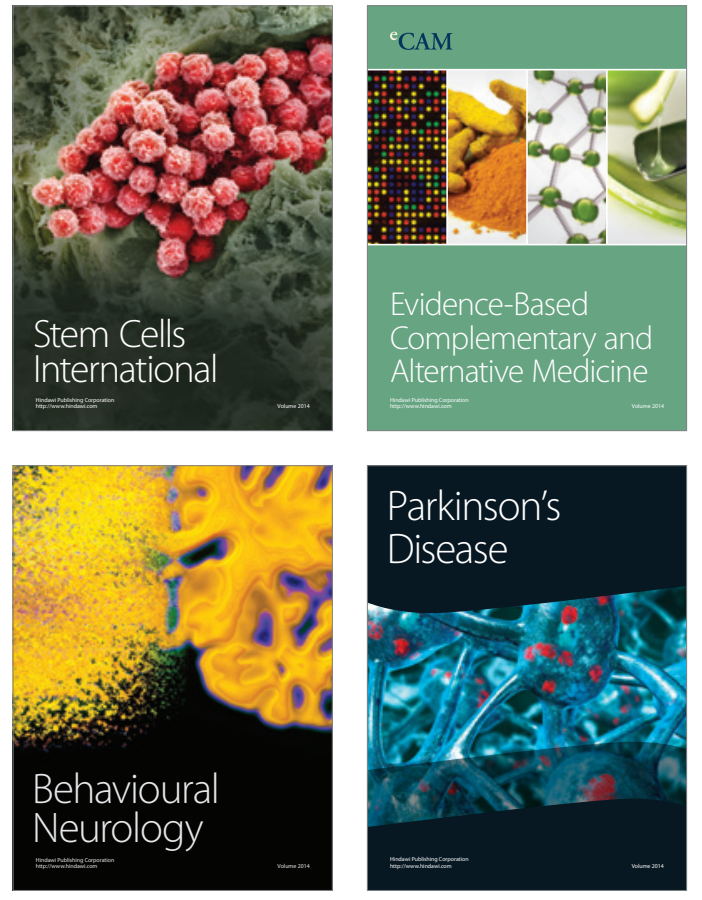
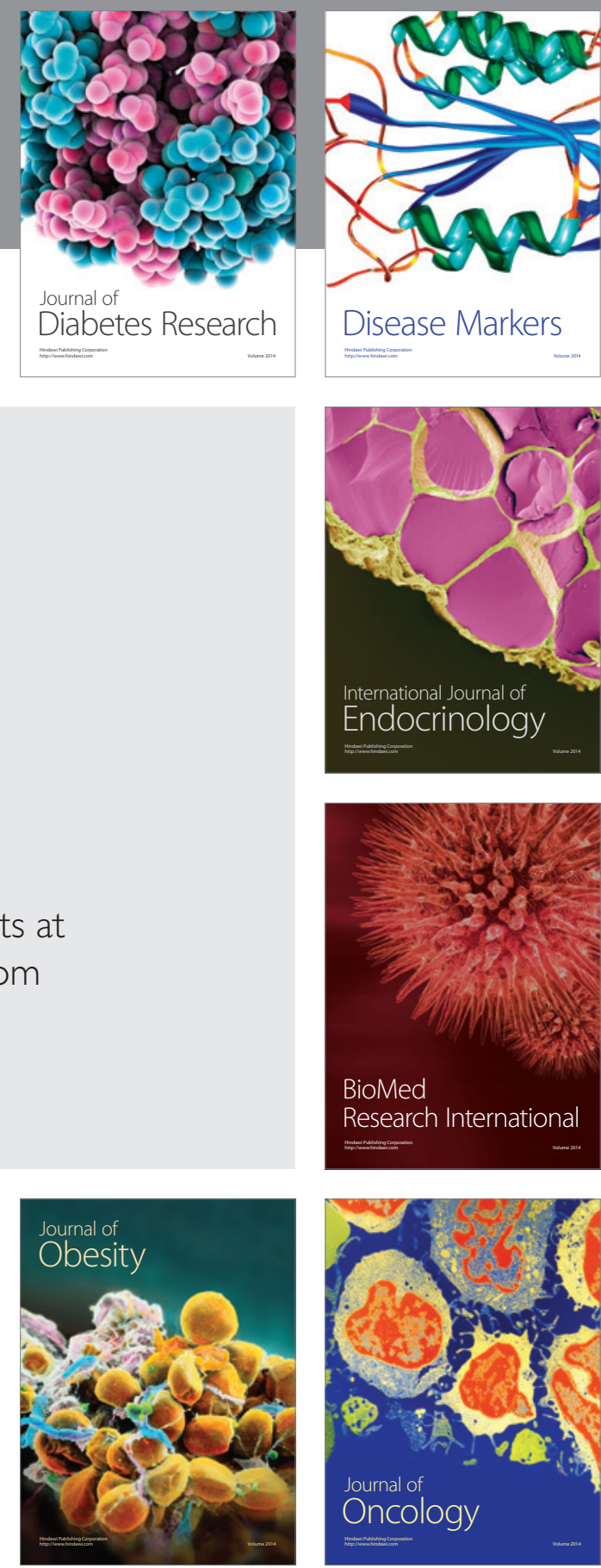

Disease Markers
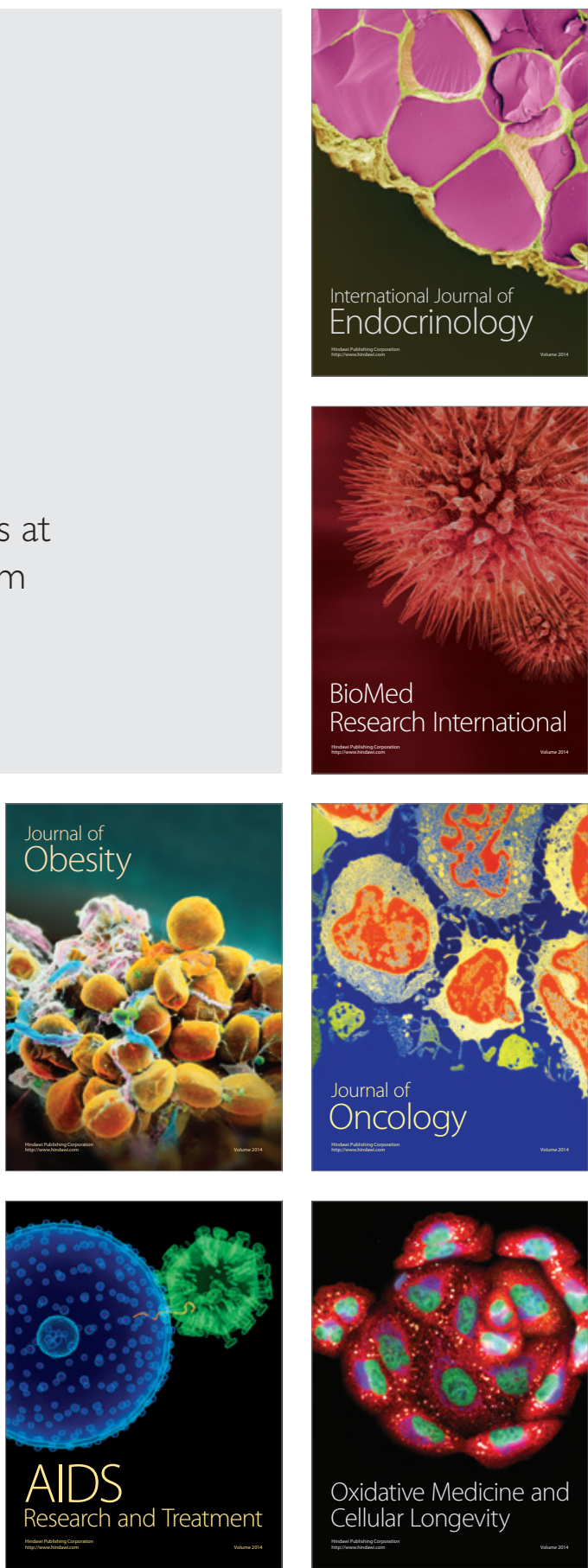